\title{
The Monte Carlo simulation of avalanche-type processes
}

\author{
A. N. BOZHINSKIY \\ Laboratory of Snow Avalanches and Mudflowes, Faculty of Geography, Moscow State University, 119992 Moscow, Russia
}

\begin{abstract}
The statistical modelling of gravitational avalanche-type processes is carried out using the Monte Carlo method. The process of snow avalanche origin is described with the model of stress state and stability of snow cover on a slope. The statistical simulation of the stress state of a snow slab is performed for avalanche site No. 22 (Khibiny, Russia). The strength characteristics of the snow slab are considered as random variables. The influence of the first moments of the distributions of the slab-strength parameters on the probability of avalanche release is studied. Using a hydraulic model of a dense flow avalanche, the statistical modelling of avalanche dynamics for the avalanche site "Domestic" (Elbrus region, Russia) is carried out. The coefficients of dry and turbulent friction and snow entrainment are considered as random parameters of the model. The histograms and distribution functions of the run-out distance, thickness and volume of avalanche depositions are obtained. The model and empirical distribution functions of the avalanche run-out distance are compared. Statistical simulation of slushflow dynamics (basin of Bear brook, Khibiny, Russia) is performed. The two-layer deterministic model of slushflow is used. The random parameters of the model assumed are: the water inflow on the "tail" of the flow and the coefficient of dry friction for slush. The histograms and distribution functions of dynamic characteristics of flow are obtained. The model outcomes are compared with field data.
\end{abstract}

\section{INTRODUCTION}

Macromechanics of gravitational avalanche-type processes (snow avalanches, slushflows and debris flows) has actively developed in recent decades. The processes of snow avalanche origin have been described (Bozhinskiy and Chernouss, 1986; Bozhinskiy and others, 2002a). Dynamic models of dense snow avalanches, powder avalanches and mixed avalanches have been proposed (Bozhinskiy and Losev, 1987; Eglit, 1998; Harbitz, 1998). Dynamic models for slushflow and debris flow have also been developed (Iverson, 1997; Bozhinskiy and Nazarov, 1998, 2000). A model usually includes some parameters, which, together with input data, control the solution of a problem. The rather precise assessments of model parameters for natural problems, including avalanche-type processes, are impossible practically. Each realization of an avalanche-type process is the result of the interaction of many complex natural factors, and thus has ultimately a probabilistic character. In this context, a probabilistic approach to the assessment of avalanche dynamic characteristics seems to be a sound perspective (Barbolini and Savi, 2001; Bozhinskiy and others, 2001, 2002a,b,c; Barbolini and others, 2002).

The object of this paper is the statistical simulation of avalanche-type processes. As a basis, deterministic models of these processes are used, but the model parameters and/or input data are treated as random variables. The output data, obtained in operating the deterministic model, will also be random variables. The statistical simulation of random parameters is carried out by the Monte Carlo method.

\section{MONTE GARLO METHODOLOGY}

The Monte Carlo method is a statistical simulation method that can simulate any process that undergoes an influence of random factors. The Monte Carlo method simulates random variables with known distribution laws. A reference random variable used in the Monte Carlo method is $\beta$, uniformly distributed within an interval $(0,1)$.

Having generated a value for $\beta$, it is possible to calculate a value $\eta$ of another random variable $x$, distributed within an interval $(a, b)$ with a probability density $p(x)$, from the equation (Sobol', 1968)

$$
\int_{a}^{\eta} p(x) \mathrm{d} x=\beta .
$$

If the variable $x$ is distributed uniformly within an interval $(a, b)$, its density $p$ is constant $\left(p=(a-b)^{-1}\right)$, and from Equation (1) follows the equation for generation of values of $\eta$ :

$$
\eta=a+\beta(b-a) .
$$

There are various ways of generating random variables for more complicated distributions of $\eta$ (Sobol', 1968). In particular, if $\eta$ is normally distributed with parameters $\xi$ and $\sigma \quad(\xi=\mathrm{E} \eta$ is the mathematical expectation; $\sigma=(\mathrm{D} \eta)^{1 / 2}$ is the sample standard deviation, with D indicating the variance) the generated values follow from the equation

$$
\eta=\xi+\sigma \eta_{0}
$$

where $\eta_{0}$ is the normal distributed random variable with zero mathematical expectation and unit variance. 


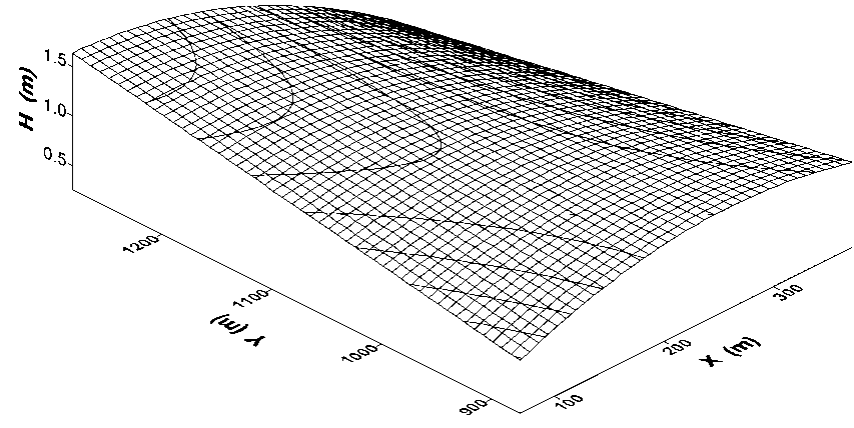

Fig. 1. Distribution of snow slab thickness; contour of $H$ level is $0.1 \mathrm{~m}$. Avalanche site No. 22 (Khibiny).

In this paper, the uniform distribution law of model parameters is used for three reasons. First, the true distribution of any model parameter is not known. Secondly, as shown earlier, the influence of the distribution laws for model parameters on distribution functions for output model characteristics is relatively weak (Bozhinskiy and others, 2001). Thirdly, the uniform distribution law is convenient for examining how the moments of distributions of model parameters influence the output data.

\section{STATISTICAL MODELLING}

\section{Snow avalanche origin}

The problem of the stability of snow on mountain slopes and avalanche origin is key in avalanche science. During statistical simulation, the model of the stress state of a snow slab on mountain slopes based on the equations of the momentless theory of thin elastic (viscous) shells was used (Bozhinskiy and others, 2002a). The zone of the avalanche origin or instability is determined by the critical thickness $H_{\mathrm{cr}}$ of a snow slab:

$$
H_{\mathrm{cr}}=c[\rho g(\sin \psi-f \cos \psi)]^{-1},
$$

where $c$ is cohesion, $f$ is the coefficient of internal friction, $\rho$ is the snow density, and $\psi$ is the local slope angle.

The output characteristics of the two-dimensional model are normal stresses $S_{11}, S_{22}$ (along and across a slope) and shear stresses $S_{12}$ in a plane of a slab. Thus, it is possible to determine an avalanche origin not only from a maximum tensile stress, which is usually observed on the upper contour (fracture line), but also by more complicated criteria, for example, the intensity $S_{\mathrm{i}}$ of shear stresses (Bozhinskiy and others, 2002a), which achieves a maximum along longitudinal edges of the instability zone (flank shear fractures):

$$
S_{\mathrm{i}}=\left(S_{11}^{2}+S_{22}{ }^{2}-S_{11} S_{22}+3 S_{12}{ }^{2}\right)^{1 / 2} .
$$

From the solution of the two-dimensional problem, it is possible to estimate a configuration of an instability zone and a volume of snow, which is potentially unstable. However, this volume practically always exceeds the actual volume of snow originally involved in the motion, because the action of maximal stresses is spread to only a part of the instability zone (Bozhinskiy and others, 2002a).

The statistical simulation of snow instability on a slope was carried out for avalanche path No. 22 (Khibiny, Russia). The stress state and stability of the snow slab before an avalanche release was estimated. The avalanche occurred on 9 February 1987, as a result of mortar firing, and had a volume

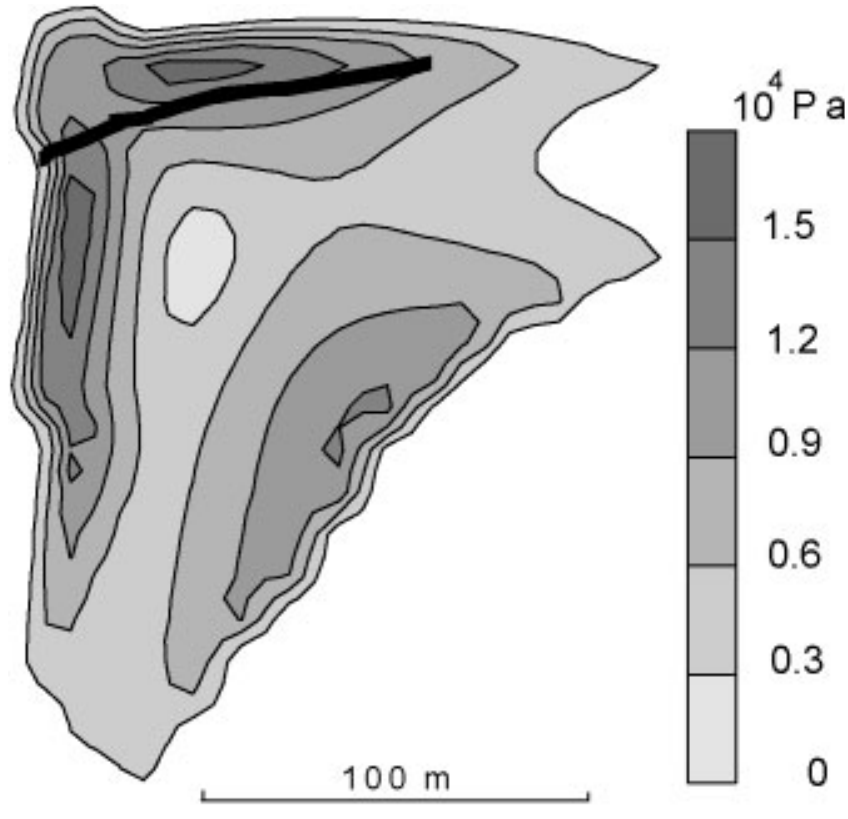

Fig. 2. Contours of shear stress intensity $S_{\mathrm{i}}$.

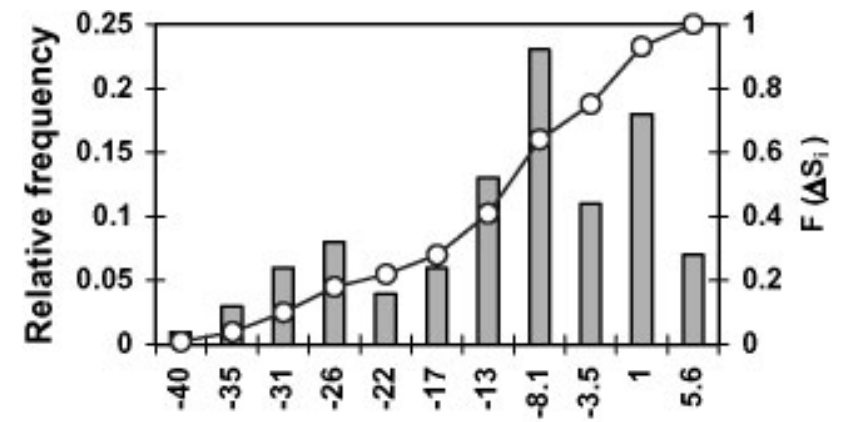

$\Delta \mathrm{S}_{\mathrm{i}} \times 10^{3}(\mathrm{~Pa})$

\section{Fig. 3. Histogram and distribution function of $\Delta S_{\mathrm{i}}$.}

of $31 \times 10^{3} \mathrm{~m}^{3}$. The distribution of the snow slab thickness within a starting zone was determined from field measurements on 40 stakes and was approximated by a cubic polynomial, as shown in Figure 1. Storm-accumulated snow is noticeable in the left upper corner of the starting zone. Data on the strength characteristics of snow are lacking, so typical ranges of values were assumed: $0.4 \leq f \leq 0.5,300$ $\leq c \leq 700 \mathrm{~Pa}$. The strength of the snow slab on rupture and shear, and accordingly the limiting value $S_{\mathrm{i}}{ }^{*}$ of the shear stress intensity in a plane of a slab, were also random. The assumed value was $1 \times 10^{4} \leq S_{\mathrm{i}}{ }^{*} \leq 2 \times 10^{4} \mathrm{~Pa}$. The assumed ranges for strength parameters approximately correspond to experimental data for storm-packed snow with a density of about $300 \mathrm{~kg} \mathrm{~m}^{-3}$ (Voitkovskiy, 1977).

A uniform distribution of strength characteristics within the assumed ranges was supposed. One hundred values of random variables $c, f, S_{\mathrm{i}}{ }^{*}$ were generated, and then the stress distributions within the avalanche starting zone are obtained. It is necessary to underline that, for a given problem, as well as for two other problems considered in this paper, the number of generations has an illustrative character.

The fragment of the starting zone, corresponding to the left upper corner of Figure 1, is shown in Figure 2. There the typical distribution of $S_{\mathrm{i}}$ is given. It is seen that the contours 


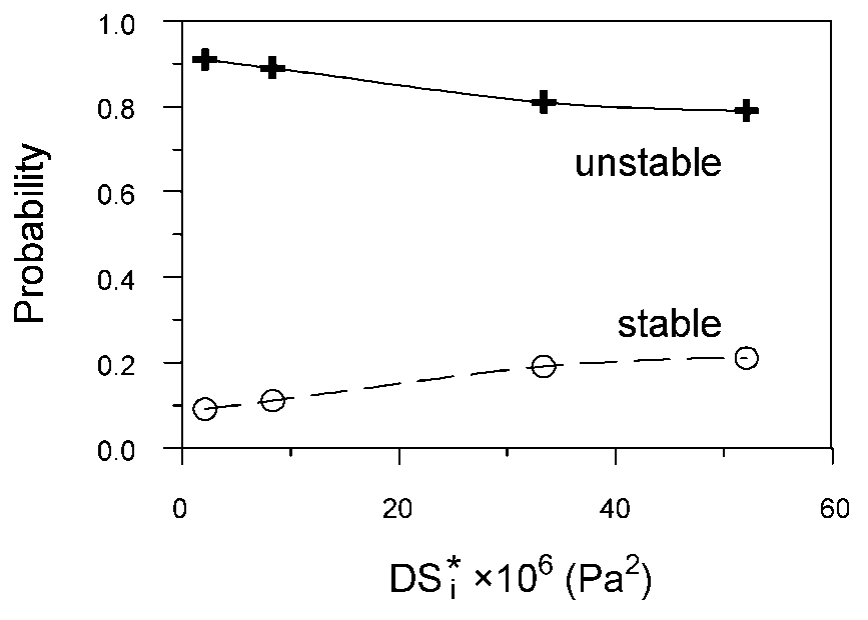

Fig. 4. Probability of snow slab instability (solid line) and stability (dashed line) vs dispersion of $S_{\mathrm{i}}$.

of the maximum stress $S_{\mathrm{i}}$ form a near-triangular shape. Maximum tensile stresses act at the crown, and maximum shear stresses and transverse normal stresses on the sides. The thick solid line marks the fracture line of the avalanche. Good agreement between the model calculations and field data is noticeable.

The maximum values $S_{\mathrm{i}}$ for each realization were compared to a random value $S_{\mathrm{i}}{ }^{*}$, and the random difference $\Delta S_{\mathrm{i}}=S_{\mathrm{i}}^{*}-S_{\mathrm{i}}$ was determined. The histogram and distribution function of $\Delta S_{\mathrm{i}}$ are shown in Figure 3. The distribution has a negative skewness and excess. By definition, $\Delta S_{\mathrm{i}}>0$ corresponds to stability and $\Delta S_{\mathrm{i}}<0$ to instability of the slab. According to the distribution function in Figure 3 , the probability of stability and instability of the snow slab is equal to 0.11 and 0.89 , respectively. The probability of instability of the snow slab is rather great, which also proves to be true of the avalanche release.

However, as the boundary values of ranges of change of snow-strength characteristics are not exact, the influence of the first moments of distributions (mathematical expectation and variance) on stability of the snow slab was investigated. In Figure 4, the curves of probability of stability and instability of the slab are shown to depend on the variance of $S_{\mathrm{i}}^{*}, \mathrm{D} S_{\mathrm{i}}^{*}$. The mean value of $S_{\mathrm{i}}^{*}, \xi_{\mathrm{S}}$, was held constant and set to $1.5 \times 10^{4} \mathrm{~Pa}$. This corresponds to expansion or narrowing of the range of changing of $S_{\mathrm{i}}^{*}$. It is apparent that the influence of the variance of $S_{\mathrm{i}}^{*}$ on stability of the snow slab is rather weak. At the same time, the dependence of the probability of snow-slab stability on the mean value of cohesion $\xi_{\mathrm{c}}$ is noticeably stronger ( $\mathrm{D} c$ is constant, which corresponds to a shift of the range of changing of $c$ ) (see Fig. 5). The curves corresponding to stability and instability of the slab draw together with increasing $\xi_{\mathrm{c}}$, and at $\xi_{\mathrm{c}} \approx 700 \mathrm{~Pa}$ the probabilities of avalanche release and snowslab stability are nearly identical and equal to 0.5. Thus, control of the process of the avalanche origin is determined by mean values of strength parameters of a snow slab, whereas the influence of variance of these parameters is secondary. This conclusion is important for modelling and should be proved by the subsequent calculations.

\section{Snow avalanche dynamics}

The following avalanche problem is connected with describing the process of an avalanche motion on a slope. Here, the

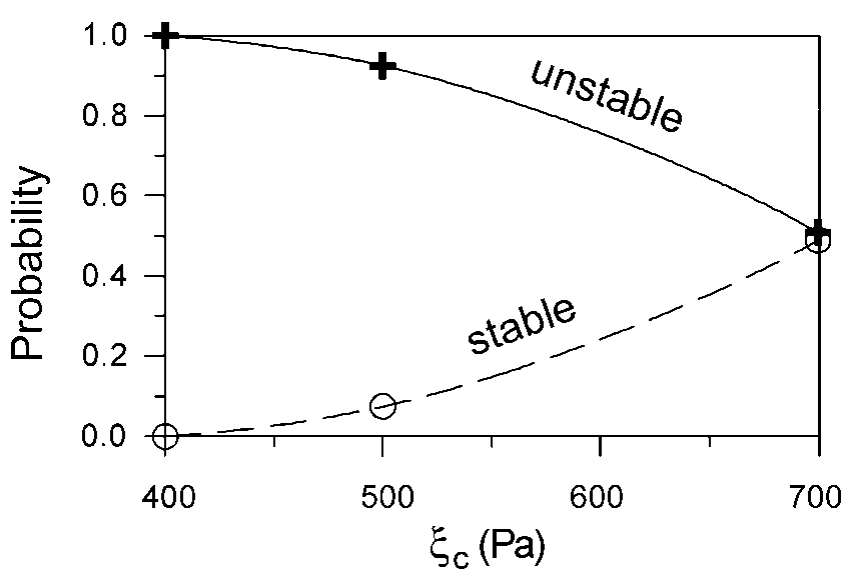

Fig. 5. Probability of snow slab instability (solid line) and stability (dashed line) vs mean value $\xi_{\mathrm{c}}$ of snow cohesion.

deterministic one-dimensional hydraulic model, which takes into account an entrainment of new snow masses into the motion, is applied (Bozhinskiy and others, 2001). Three parameters of the model, namely, coefficients $\mu, k$ of dry and turbulent friction, respectively, and the coefficient $m_{\mathrm{e}}$ of the snow mass entrainment into the motion, are considered as random variables. The statistical simulation of the avalanche-motion process is carried out for the well-known avalanche path "Domestic" (Elbrus region, Russia), where there is a series of field observations of run-out distances (38 events). The uniform distribution of random model parameters within ranges $0.15 \leq \mu \leq 0.525,0.005 \leq k \leq$ 0.2 , and $0.002 \leq m_{\mathrm{e}} \leq 0.01$ was assumed. The mean values of $\mu$ and $k$ were assumed based on several back model calculations of actual avalanches. The boundaries of ranges cannot be prescribed precisely, and naturally contain some indeterminacy, but they correspond to rather rare avalanches (short and long run-out distances). The boundaries of $m_{\mathrm{e}}$ correspond approximately to one-quarter and total erosion of snow cover. The remaining model parameters and input data were deterministic and set to an average value. The density $\rho$ of the avalanche body was equal to $200 \mathrm{~kg} \mathrm{~m}^{-3}$, the snow-cover thickness in a transit and deposition zone $H_{0}=1.5 \mathrm{~m}$, and the initial volume (per unit of width) of snow involved in the motion, $V_{0}=50 \mathrm{~m}^{2}$.

Two hundred values of random model parameters were generated. As a result of statistical simulation, the 200-term series of the following output model characteristics were obtained: the run-out distances of avalanches, the maximum thickness of depositions, the time of motion, and the volume and length of an avalanche deposit body.

The statistics (the mathematical expectation $\xi$, the sample standard deviation $\sigma$, the coefficient of skewness $\gamma_{\mathrm{a}}$, the coefficient of excess $\gamma_{\mathrm{e}}$, the coefficient of variation $C_{\mathrm{v}}$ ) of

Table 1. Statistics of model and empirical distributions of runout distance (avalanche site "Domestic")

\begin{tabular}{rcc}
\hline & Model & Empirical \\
\hline$\xi$ & $1613 \mathrm{~m}$ & $1614 \mathrm{~m}$ \\
$\sigma$ & $47 \mathrm{~m}$ & $84 \mathrm{~m}$ \\
$\gamma_{\mathrm{a}}$ & -0.39 & -0.48 \\
$\gamma_{\mathrm{e}}$ & 0.84 & 0.40 \\
$C_{\mathrm{v}}$ & 0.029 & 0.052 \\
\hline
\end{tabular}




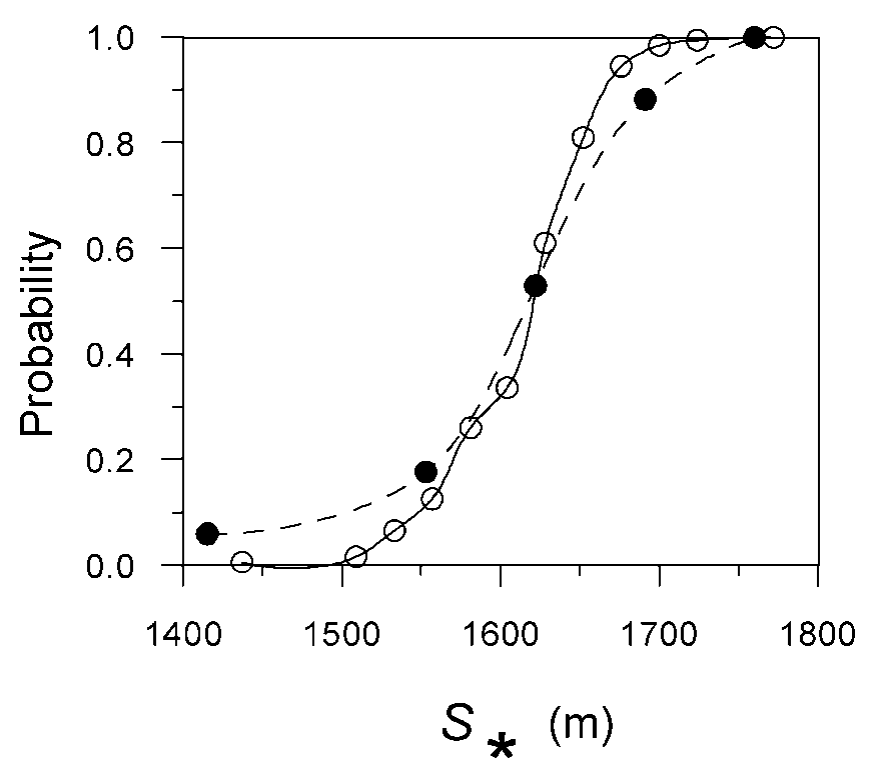

Fig. 6. Model and empirical distribution function of avalanche run-out. Avalanche site "Domestic".

the empirical and model run-out distance $S^{*}$ are shown in Table 1 . The mean values of distributions practically coincide; also, the coefficients of skewness are close. The scatter of model values is less noticeable. Moreover, the model distribution has a more acute peak. A comparison of the model and empirical cumulative distribution functions $F\left(S^{*}\right)$ of the run-out distance is depicted in Figure 6. According to the Kolmogorov-Smirnov test, the maximum value of the module of the difference is used as a measure of deviationmodel (m) and empirical (e) distributions (Ventsel, 1969):

$$
d=\max \left|F_{\mathrm{e}}\left(S^{*}\right)-F_{\mathrm{m}}\left(S^{*}\right)\right| .
$$

Then the value $\lambda=d N^{1 / 2}$ is determined, where $N$ is the number of observations, and under the relevant table the probability $p(\lambda)$ is found, which means that the discrepancy between model and empirical distributions will be not less than the actually observed one. In the case under consideration, $d \approx 0.12, N=38, \lambda \approx 0.7$ and $\rho(\lambda) \approx 0.7$. This probability is not small; therefore, it is possible to consider a hypothesis about the goodness of model and empirical distributions compatible with data from field observations. The hypothesis is also not rejected according to Pearson's chisquare test. At the same time, some discrepancy is found in zones of rather rare values, which is due to both ignorance of precise distribution laws of model parameters, and restricted series of field observations.

The histogram and distribution function of the maximum thickness of avalanche depositions are shown in Figure 7. The distribution is characterized by positive asymmetry $\left(\gamma_{\mathrm{a}}=0.63\right)$ and almost by lack of excess $\left(\gamma_{\mathrm{e}}=-0.11\right)$. The mean value is $\xi_{\text {Hmax }}=5.5 \mathrm{~m}$. This value is in accordance with field observations, which, unfortunately, are unit.

\section{Slushflow dynamics}

The two-layer deterministic hydraulic model of a slushflow is a basis for developing a probabilistic model of a slushflow and statistical simulation (Bozhinskiy and Nazarov, 1998).

Series of numerical experiments using the model have shown that the coefficient $\mu$ of dry friction of slush and the intensity $Q$ of a water inflow on the "tail" strongly influence dynamic characteristics, run-out distance, thickness and

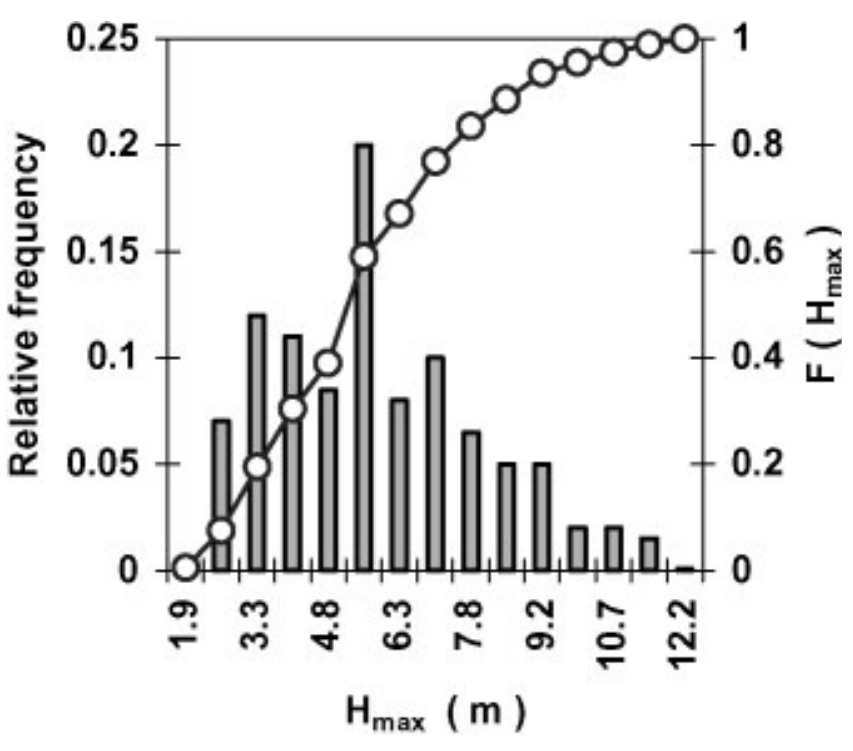

Fig. 7. Histogram and distribution function of $H_{\max }$. Avalanche site "Domestic".

volume of slushflow depositions. The influence of the other model parameters is weaker. In this connection, the following model parameters were assumed to be deterministic: the drag coefficients $k_{\mathrm{s}}, k_{\mathrm{w}}, k_{\mathrm{sw}}$ of the turbulent flow of slush and water over the snow-cover surface and over the slushwater interface, respectively, and the intensity $\theta$ of water percolation from the lower to the upper layer. Morphometric parameters of the slope were also considered as prescribed.

It was supposed that the inflow $Q$ of water on the "tail" of the flow damps in time $(t)$ within 600 s under the square law

$$
Q=Q_{0}\left[1-(t / 600)^{1 / 2}\right]
$$

The parameters $\mu$ and $Q_{0}$ were considered as random. The uniform distribution law was accepted. The statistical simulation of slushflow dynamics was carried out for basin No. 166, which is located on the western slope of Khibiny in the basin of Bear brook. Tracks of slushflow, released presumably in 1950/51, 1968/69 and reliably in 1977 and 1984, are traced on terrain. The slushflow in 1984 left the most numerous and reliable tracks, making it possible to produce a survey of boundaries and to determine some parameters of slushflow. The flow has passed $3.35 \mathrm{~km}$ up the channel. The height of the leading front reached $>10 \mathrm{~m}$. The basic mass of wet snow was deposited by the extended "tongue", about $250 \mathrm{~m}$ long and up to $40 \mathrm{~m}$ wide. The total volume of snow deposits was of the order of $3.5 \times 10^{4} \mathrm{~m}^{3}$. The run-out distance of slushflow in 1984 was not maximal. From the character of depositions on boards and at the bottom valley, the age of new growth and damages on tree trunks, it appears that in the beginning of the 1950s, slushflows advanced $900 \mathrm{~m}$ further (Bozhinskiy and others, 2002c).

The data from field observations and morphometric parameters of the slope were used during statistical simulation of slushflow dynamics. From a relation of water and snow masses in slushflow it was assumed $Q_{0 \mathrm{~min}}=5 \mathrm{~m} \mathrm{~s}^{-1}$, $Q_{0 \max }=15 \mathrm{~m} \mathrm{~s}^{-1}$. The minimum value $\mu_{\min }$ of the coefficient of dry friction was estimated according to the possibility of model slushflow reaching the visual boundaries on the terrain, and was equal to 0.1 . The maximum value $\mu_{\max }$ was assumed equal to 0.2 . The values of the deterministic 
Table 2. Statistics of model distributions of output characteristics of slushflow (Bear brook, Khibiny)

\begin{tabular}{lcccccccc}
\hline & $S$ & $l_{\mathrm{s}}$ & $l_{\mathrm{sw}}$ & $H_{\mathrm{s}}$ & $H_{\mathrm{w}}$ & $V_{\mathrm{s}}$ & $V_{\mathrm{w}}$ & $T$ \\
\hline$\xi$ & $2722 \mathrm{~m}$ & $370 \mathrm{~m}$ & $118 \mathrm{~m}$ & $15.2 \mathrm{~m}$ & $5.80 \mathrm{~m}$ & $2651 \mathrm{~m}^{2}$ & $1731 \mathrm{~m}^{2}$ & $570 \mathrm{~s}$ \\
$\sigma$ & $529 \mathrm{~m}$ & $60 \mathrm{~m}$ & $28 \mathrm{~m}$ & $1.97 \mathrm{~m}$ & $2.02 \mathrm{~m}$ & $510 \mathrm{~m}^{2}$ & $637 \mathrm{~m}^{2}$ & $121 \mathrm{~s}$ \\
$\gamma_{\mathrm{a}}$ & -0.30 & -0.46 & 0.57 & -0.07 & 0.55 & -0.32 & -0.01 & -0.11 \\
$\gamma_{\mathrm{e}}$ & 1.24 & -0.75 & -0.31 & -0.65 & -0.58 & 1.29 & -1.33 & 0.30 \\
$C_{\mathrm{v}}$ & 0.19 & 0.16 & 0.24 & 0.13 & 0.35 & 0.19 & 0.37 & 0.21 \\
\hline
\end{tabular}

model parameters were set to: snow porosity $P=0.5$; $k_{\mathrm{s}}=k_{\mathrm{w}}=0.03, k_{\mathrm{sw}}=0.02 ; \theta=0.05$. The snow-cover thickness in the channel was $H_{\mathrm{c}}=1 \mathrm{~m}$; the density of involved snow was equal to $450 \mathrm{~kg} \mathrm{~m}^{-3}$. The value of the coefficient of snow entrainment was assumed such that the snow accumulated in the channel was completely involved in the motion according to field observations.

Fifty values of random variables $\mu, Q_{0}$ were generated, and then, using the two-layer model of slushflow, 50 numerical experiments were carried out. Thus, the 50-term series of the following output model characteristics were obtained: the run-out distance $S$; the length $l_{\mathrm{s}}$ of a zone of slushflow depositions; the length $l_{\mathrm{sw}}$ of the lower water layer; the maximal thickness $H_{\mathrm{s}}$ of snow depositions; the maximal depth $H_{\mathrm{w}}$ of the lower water layer; the volume (per unit width) $V_{\mathrm{s}}$ of snow depositions and the total volume of water $V_{\mathrm{w}}$; the time of motion $T$. The outcomes of the statistical simulation of slushflow dynamics are shown in Table 2 and Figure 8. It is necessary to emphasize that the distributions of all output model characteristics, excluding $V_{\mathrm{w}}$, have appeared essentially non-uniform, though the input distributions of $\mu$ and $Q_{0}$ were uniform. This outcome is due to non-linearity of the operator of the slushflow dynamic model. In addition, it is possible to note that the majority of distributions are characterized by rather weak asymmetry. At the same time, the coefficients of excess of distributions noticeably differ (from 1.24 to -1.33 ).

The distribution of the run-out distance of slushflow is characterized by positive excess. Figure 8 testifies to a concentration of stop points of the leading front of slushflow within a slope-length interval of 2700-3200 m. For gravitational avalanche-type flows, as a rule, this is due to morphometric peculiarities of a profile of a channel in this interval (a flattening zone of a slope). According to the distribution

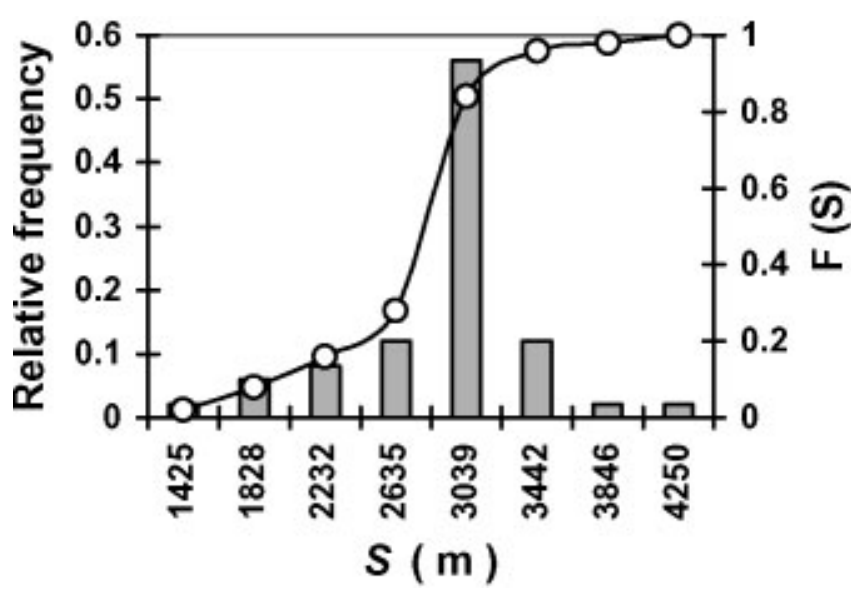

Fig. 8. Histogram and distribution function of slushflow runout. Bear brook, Khibiny. function obtained, the run-out distance of slushflow in 1984 approximately corresponds to a probability of 0.05 . The distant run-outs are rather rare; their realization requires a combination of considerable water inflow on the "tail" and low coefficients of dry friction.

\section{GONGLUSION}

This paper illustrates the possibilities of applying the Monte Carlo method for statistical simulation of avalanche-type processes, using the restricted field information usually available. For more precise estimations of the characteristics of avalanche-type processes, a greater number of random model parameters and input data is needed. With a sequential increase in the number of random model parameters, the distribution functions of output characteristics will deform (Bozhinskiy and others, 2001). In the end, they should converge to limiting distribution functions, which will be practically "rigid" (undeformed). In essence, these limiting distribution functions will compensate our ignorance of the true distribution of model parameters. The number of generations will depend on both the necessary accuracy and the number of random parameters.

\section{ACKNOWLEDGEMENTS}

The Russian Fund of Basic Researches, grant No. 02-0564667, financially supported this paper. P. A. Chernous provided the field data on avalanche site No. 22; L. A. Sukhanov and A. D. Oleynikov collected the run-out distances for avalanche site "Domestic". Many thanks to all of them.

\section{REFERENGES}

Barbolini, M. and F. Savi. 2001. Estimate of uncertainties in avalanche hazard mapping. Ann. Glaciol., 32, 299-305.

Barbolini, M., C. J. Keylock and F. Savi. 2002. Statistical methods for the evaluation of friction coefficients in avalanche hazard mapping. Mater. Glyatsiol. Issled./Data Glaciol. Stud., 93, 88-99. [In English with Russian summary.]

Bozhinskiy, A. N. and P. A. Chernouss. 1986. Veroyatnostnaya model' ustoychivosti snega na sklonakh gor [Probability model of snow stability on mountain slopes]. Mater. Glyatsiol. Issled. 55, 53-60. [In Russian with English summary.]

Bozhinskiy, A. N. and K. S. Losev. 1987. Osnovy lavinovedeniya [Fundamentals of avalanche science]. Leningrad, Gidrometeoizdat. [In Russian with English table of contents.] (Translated by C. Bartelt, SFISAR Special Report.)

Bozhinskiy, A. N. and A. N. Nazarov. 1998. Dynamics of two-layer slushflow. In Hestnes, E., ed. 25 Years of Snow Avalanche Research, Voss, 12-16 May 1998. Proceedings. Oslo, Norwegian Geotechnical Institute, 74-78. (NGI Publication 203.)

Bozhinskiy, A. N. and A. N. Nazarov. 2000. Two-phase model of debris flow. In Wieczorek, G. F. and N. Naeser, eds. Debris flow hazards mitigation: mechanics, prediction and assessment. Rotterdam, A.A. Balkema, 263-269.

Bozhinskiy, A. N., A. N. Nazarov and P. A. Chernouss. 2001. Avalanches: a probabilistic approach to modelling. Ann. Glaciol., 32, 255-258. 
Bozhinskiy, A. N., A. N. Nazarov and P. A. Chernouss. 2002a. A probabilistic model of snow avalanche origin and motion. Mater. Glyatsiol. Issled.) Data Glaciol. Stud., 93, 79-84. [In English with Russian summary.]

Bozhinskiy, A. N., L. A. Sukhanov, Yu. B. Andreev and T. L. Sidorova. 2002b. Probabilistic zoning of avalanche paths and risk estimation. $M a-$ ter. Glyatsiol. Issled./Data Glaciol. Stud., 93, 117-121. [In English with Russian summary.]

Bozhinskiy, A. N., A. N. Nazarov and V. N. Sapunov. 2002c. Statisticheskoe modelirovanie dynamiky vodosnezhnykh potokov [Statistical modeling of slushflow dynamics]. Vestnik Moskovskogo Universiteta, Ser. 5. Geografii, 39-43. [In Russian with English summary.]

Eglit, M. 1998. Mathematical modeling of dense avalanches. In Hestnes, E. ed. 25 Years of Snow Avalanche Research, Voss, 12-16 May 1998. Proceedings.
Oslo, Norwegian Geotechnical Institute, 15-18. (NGI Publication 203. Harbitz, C. B. 1998. A survey of computational models for snow avalanche motion. In Harbitz, C.B., ed. SAME snow avalanche modelling, mapping, and warning in Europe. Oslo, Norwegian Geotechnical Institute, 23-71. (NGI Report 581220-1.)

Iverson, R.M. 1997. The physics of debris flows. Rev. Geophys., 35(3), 245-296. Sobol', I. M. 1968. Method Monte Carlo [The Monte Carlo method]. Moscow, Nauka. [In Russian.]

Ventsel, E. S. 1969. Teoriya veroyatnostey [The probability theory]. Moscow, Gostechizdat. [In Russian.]

Voitkovskiy, K. F. 1977. Mekhanicheskie svoystva snega [Mechanical properties of snow ]. Moscow, Nauka. Sibirskoye Otdelenie. Institut Merzlotovedeniya. [In Russian.] 